\title{
A History of the World in Twelve Maps
}

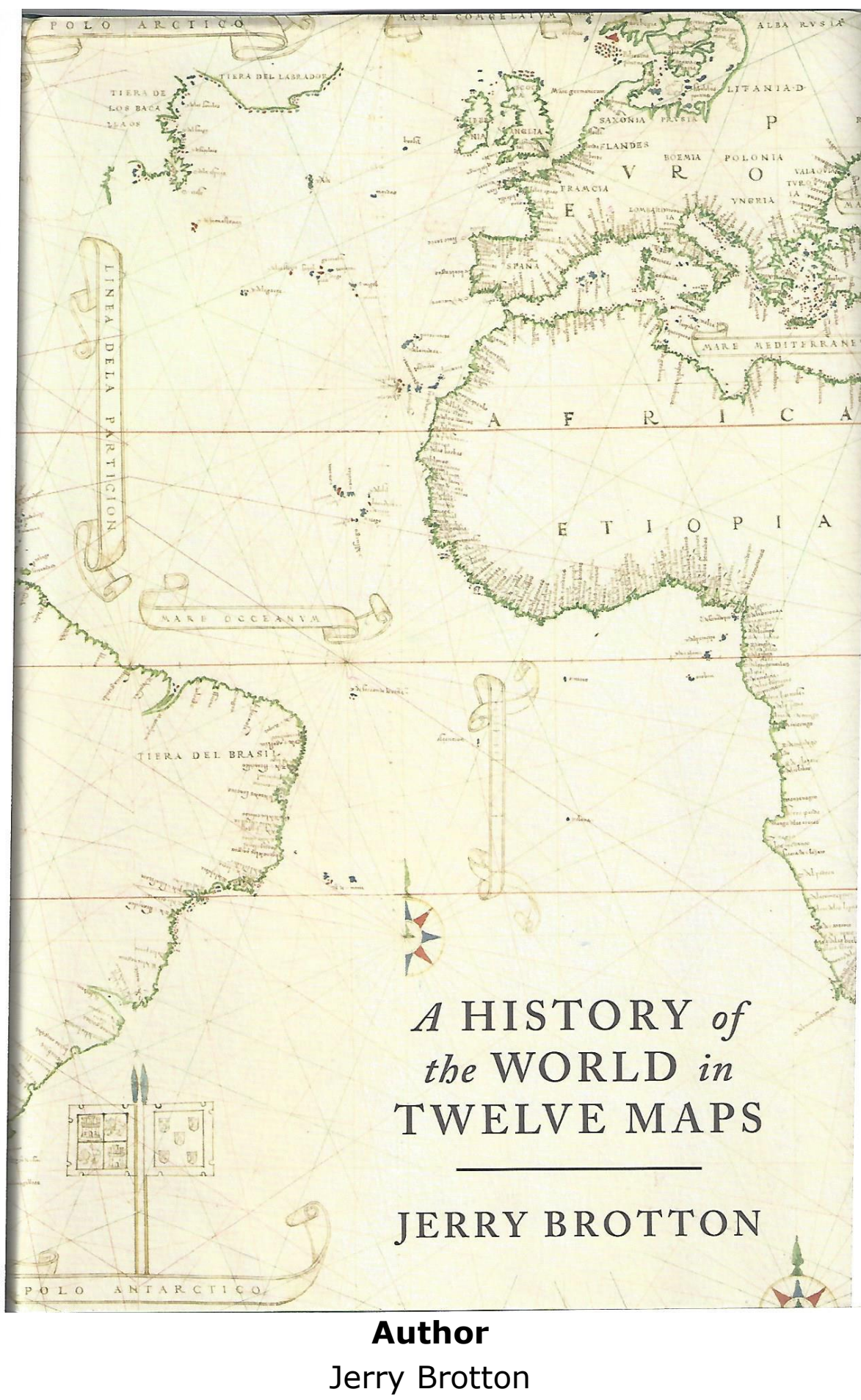

Renaissance Studies at Queen Mary University of London, UK 


\title{
Reviewer
}

\author{
Niyazi KAYA ${ }^{1}$ \\ National Ministry of Education, Ankara, TURKEY
}

Publisher: Allen Lane

Publication Year: 2012

Edition: First Edition Pages: $514+$ xviii Price: $£ 32.99$

ISBN : 978-0-141-03493-5

Jerry Brotton is Professor of Renaissance Studies at Queen Mary University of London. In his recent work Jerry Brotton, as a leading expert in the history of maps and Renaissance cartography, presents the histories of twelve maps belonging to different eras from the mystical representations of ancient times to Google Earth. He examines the stories of these twelve maps as having important roles in the context of regional and global perspectives of past and today's world. His book is an interesting and significant contribution to the interdisciplinary approach between history and geography. In addition to the twelve maps, thirty four figures and fifty six illustrations are included in this book, which aims to tell history through maps.

All of the maps chosen by the author should not be regarded as the best ones of their times. Conversely, many of them were heavily criticized at the moment of their completion. Some maps were neglected at the time or subsequently dismissed as outdated or obscure. The author stresses that all the maps he analyzed in detail bear witness that one way of trying to understand the histories of our world is by exploring how the spaces within it are mapped (p.16). The maps studied in this book are as follows:

- Science: Ptolemy's Geography, c. 150

- Exchange: Al-Idrîsî, 1154

- Faith: Hereford Mappamundi, c. 1300

- Empire: Kangnido World Map, 1402

- Discovery: Martin Waldseemüller, World Map, 1507

- Globalism: Diego Riberio, World Map, 1529

- Toleration: Gerard Mercator, World Map, 1569

- Money: Joan Blaeu, Atlas Maior, 1662

- Nation: The Cassini Family, Map of France, 1793

- Geopolitics: Halford Mackinder, The Geographical Pivot of History, 1904

- Equality: The Peters Projection, 1973

- Information: Google Earth, 2012

${ }^{1}$ Dr. Niyazi KAYA, an education expert in National Ministry of Education in Ankara, Turkey, niyakaya [at] gmail.com 
As is shown by the title of each map, the author has preferred to give labels for the maps by referring their characteristics in the context of global history. It is not clear why the author chose these maps as subject of his book. As an historian of the Renaissance, Brotton gives much more attention to the 16th century, for which he describes three maps. He does not mention any maps that came onto scene in the 19th century.

The introduction begins with the story of Babylonian Map of the World in order to highlight the urge to map as a basic, enduring instinct (p.4). In each part the reader has an opportunity to learn significant characteristics of the era in which the selected maps came onto the scene chronologically. Each chapter takes the attention of the reader into not only a different kind of map but also into a different time span. Brotton clearly argues that cultures create their world view through the maps. The process of map making and reaction through the producers/makers of maps has been presented in this series of in-depth studies. This starts with the Greco-Roman geographer Ptolemy and ends with Google Earth. The author uses flash backs and makes comparisons between different maps.

Brotton offers a way to understand the worlds that produced each maps by reading them. As he states, ever since Ptolemy individuals and organizations have appropriated world maps for their own symbolic and political ends, regardless of the cartographer's claims to comprehensiveness and objectivity. Brotton shows the history of map-making is much more than a history of technical improvements; rather it is an embodiment of human values.

The works made hitherto today usually focus on how such maps have affected developments in history. However, the reasons for map makers to produce maps and show the distinctive characteristic of maps from previous and successive ones, note differences and similarities of all maps, and indicate reactions as adverse criticism or appreciation, has not been studied until the publication of "A History of the World in Twelve Maps". It should be noted that writing the history of these maps deserves the attention of all interested in the history of the world. 